Gateways into writing: a social-semiotic lens on eight to eleven year olds' evolving modes of thematic progression

Frances Bodger

Institute of Education, UCL, London, UK

20, Bedford Way, London WC1H 0AL

F.Bodger@ucl.ac.uk

6,998 words inclusive of abstract, keywords, tables, figures (with captions) and references 


\section{Gateways into writing: a social-semiotic lens on eight to eleven year olds' evolving modes of thematic progression}

Children's evolving use of sentential theme position reflects the emergence of an individual writing style differentiated from their spoken language. Choice of theme position indicates both the linguistic tools available to the writer and the structure being imposed across the text. Previous research suggests that manipulation of theme position can be challenging to learn but is important for 'knowledge-transformation' (Bereiter and Scardamalia 1987). In the light of social-semiotic research suggesting that young writers 're-make' (Kress 1996, 228) those conventions which become socially or intellectually meaningful to them, this article reports on longitudinal research which used an analysis framework informed by Systemic Functional Linguistics (SFL) to chart the evolution of theme use and modes of thematic progression in the writing of 24 children from the age of eight to eleven years. In particular, the research sought to identify potential 'gateways' (Halliday 1993) into new worlds of meaning afforded by alternative modes of thematic progression. Findings reveal interdependence between writer motivation, linguistic knowledge and content knowledge in the appropriation of established conventions for thematic progression. Writers' active engagement with, and analysis of, content knowledge was identified as the driving force behind these transformations.

Keywords: eight to eleven year olds' writing, social-semiotic theory, knowledgetransformation, theme, thematic progression,

\section{Introduction}

It is widely acknowledged that writing education in England is currently characterised by a didactic, transmission approach underwritten by a view of writing development where what 'counts' is 'organisation of material, use of prescriptive grammar, accurate spelling... and fluent handwriting' (Bearne 2017, 74). This approach divorces writing 
from the communicative contexts in which its characteristic structures evolved and are meaningful. A range of recent papers illustrate how writer motivation is dampened by such a regime (Lambirth 2017; Edwards and Jones 2018; Barrs 2019) while scope to develop writer voice becomes restricted (Fisher 2009; Gardner 2018).

More contextualised writing instruction requires knowledge of the contexts which scaffold understanding of the rationale behind linguistic forms. Discussing how children simultaneously learn language and learn through language, Halliday $(1993,98)$ identifies 'magic gateways' as contexts which support children in 'finding a special way in ... to a different world of meaning'. In the context of Secondary education, research in the tradition of Halliday's Systemic Functional Linguistics (Lemke 1990; Coffin 2006; Lim and Kellogg 2008) has identified a symbiotic relationship between discipline-specific linguistic knowledge and conceptual understanding when learning academic disciplines; immersion in historical or scientific reasoning seems to provide a 'magic gateway' to the production of linked linguistic structures.

Whilst there is evidence that 'a differentiated writing style' (Perera 1984, 247) emerges in the period of Primary to Secondary school transition, there remains scant understanding about 'gateways' prior to these younger children's full induction into academic discourses. Children's evolving use of theme position and thematic progression are potentially illuminating in this regard, being indicative of both the linguistic tools available to the writer and the structure being imposed across sentences. This article reports on SFL-informed longitudinal research into eight to eleven yearold's experimentation with theme position and thematic progression, the aim being to identify 'gateways' into new modes of thematic progression for this age group. 


\section{Theme and thematic progression}

Theme is defined as 'the element that serves as the point of departure of the message; it is that which locates and orients the clause within its context' Halliday and Matthiessen $(2014,89)$. Specifically, 'the Theme of a clause is the first group or phrase that has some function in the experiential structure of the clause, i.e. that functions as a participant, a circumstance or the process.' (op cit, 91). The theme usually expresses previously mentioned, 'given' information, with the 'new' generally appearing in the latter half of the clause (the rheme). As Halliday and Matthiessen (op cit, 126) stress, choice of 'clause Themes plays a fundamental part in the way discourse is organized' constituting the 'method of development' or mode of thematic progression of the text.

The three main types of thematic progression identified by Danes (1974) remain seminal for those researching students' thematic choices. These are:-

(1) Simple linear progression: The rheme of the first sentence becomes the theme of the second. 'George smote the dragon. The dragon fell to the ground and the earth trembled at the impact'.

(2) Thematic progression with a continuous theme. 'The explorer is fascinated by travel. He has almost boundless energy and.....'

(3) Thematic progression with derived themes. The initial sentence has a theme/ rheme structure which consists of a hyper-theme, subsequent 'new' themes becoming sub-themes. 'Blackpool is one of England's most popular holiday resorts. The tower is one of the most recognisable features of its landscape. ..' (paraphrased from Harris and Wilkinson 1986, 183). 
Evolving modes of thematic progression and the emergence of a differentiated writing style

Many characteristic features of written language have evolved to enable seamless thematic progression. Theme position tends to be exploited and is frequently characterised by 'nominalization', that is, the process of turning a conjunction, verb or attribute into a noun (Coffin 2006, 420). Such 'informational thematisation' (Martin $1986,59)$ represents an abstract construal of reality and texts which '[move] forward in logical steps each building on what has gone before' (Halliday 1993, 111), and 'welloriented to a reader looking for information' (Martin op cit.). In contrast, spoken language, which is usually unplanned and constructed jointly between participants, tends to be characterised by 'interactional thematisation' (Martin 1986, 59; Berry $1995,64)$, with 'I' and 'you' frequently used in theme position.

Although Halliday does not directly discuss how young writers learn informational thematisation, he recognises both the comprehension and production of 'synoptic' written language to be demanding, requiring a shift in perspective from representing the world congruently to a more abstract representation, which permits analysis (1993). The few detailed studies alluding to the use of theme position and modes of thematic progression with primary-aged children (Berry 1995; Christie 2010; Perera 1984) suggest that the shift from more 'speech-like' to more 'writing-like' modes of thematic progression provides a useful marker of the emergence of a 'differentiated writing style' (Perera 1984). Christie $(2010,149)$ argues that the nine to thirteen age range is characterised by increased control over hierarchical modes of thematic progression (HTP) such as Danes' 'Simple Linear Progression' and 'Thematic Progression with Derived Themes'. While there is consensus across academic disciplines that increased 
use of HTP reflects inter-related linguistic and conceptual development the three disciplines to follow provide their own explanations of the learning process.

\section{Linguistic perspectives}

Linguists (Christie 2010; Hawes 2014; Myhill 2009b) argue that while there is a developmental trajectory towards a broadening of thematic options from the end of Primary school, many older students continue to draw on a limited range which reduces their scope to produce goal-directed writing. With reference to research with thirteen to sixteen year olds, Myhill $(2009 b, 410)$ identifies that 'weaker writers', irrespective of age, tend to repeat the personal pronoun in theme position leading to 'writing that was very plot-driven, with limited description or emotional contextualisation'. Hawes (2014, 97) meanwhile observes that in the writing of international adult students on a pre-MA course "[thematic progression with continuous theme] was used disproportionately often by weaker students, resulting at worst in a series of unrelated statements about a topic theme'. Myhill $(2009 \mathrm{~b}, 411)$ argues that the ability to produce 'knowledgetransforming' writing (Bereiter and Scardamalia 1987) is 'in part at least, about linguistic development specifically in terms of how sentences are shaped and patterned'.

\section{Cognitive psychological perspectives}

An affordance of the written mode is the opportunities it offers for reflection on content knowledge. Bereiter and Scardamalia's (1987) research suggests that from around fourteen, some teenagers recognise such affordances and engage in goal setting during the planning stage of writing, achieving some sort of 'knowledge-transformation' as a result. However, such goal-oriented writing is more cognitively challenging than recalling knowledge relevant to the subject area (knowledge-telling), and may be avoided despite potential rewards. Research across age groups illustrates how the 
manipulation of writing context can foster such writing. It is well established that children are likely to engage in more 'knowledge transformation' when writing about topics in which they have some depth of content knowledge because 'knowledge accessed by the short-term working-memory is more interconnected' (McCutchen 2000, 19). Action-research from the practitioner perspective stresses that children are more likely to transform their knowledge and use 'high-level forms of language' (Kelly et al 2009, 118) when writing about 'their interests and concerns' (Ellis 2005, 54), e.g. when reflecting in journals about personal experience from the perspective of distance, where 'the act of writing becomes another way of knowing' (King 2000, 27).

\section{Social-constructivist and social-semiotic perspectives}

From a social-constructivist perspective, language is learnt implicitly 'by peripheral participation in literacy events' through writer-identification with the 'values, beliefs, goals and activities of those who engage with these practices' (Barton and Hamilton 2000, 235). Such identification serves to 'sustain and guide agency' (Dyson 2004, 95) through the writing process and enables inexperienced writers to draw on their own 'funds of knowledge' (Moll et al 2013, 172) which are evidenced through the 'hybrid' texts created, which are becoming increasingly multi-modal in nature (e.g. Kamberlis 2001; Schwartz 2014; Kelly et al 2009).

Social semioticians Kress $(1994,1996)$ and Halliday (1993) agree that language is 're-made' (Kress 1996, 228) in social contexts as the meaning represented by written forms becomes relevant to a writer's social or intellectual needs. Importantly, both stress that it is the appropriated forms themselves which provide the building blocks for further language learning, as linguistic and conceptual understandings evolve in a reciprocal, 'dialectic' (Halliday 1991, 61) process. This reciprocity is evident in Kress's $(1994,71)$ account of the evolution of the sentence in children's writing, from 'loosely 
constructed joined clauses related to the same topic... to a structure in which a more restricted topic is treated by a closer integration of clauses', illuminating the various reconstitutions of grammar which lead to theme position becoming increasingly prominent in each sentence.

In all three accounts, learning to use writing as a tool for reflection or knowledge development is pivotal. The linguistic account glosses how learning linguistic conventions for hierarchical thematic progression facilitates knowledge-transformatory modes of writing, whilst cognitive psychology glosses the learning of meta-cognitive processes for the same ends. Rather than being concerned with how mature writing conventions are 'acquired', social-semiotic accounts focus on how and why the writer comes to 're-make' the convention to meet his or her own meaning requirements. Though barely used as a tool for analysis in the Primary context, this writer-oriented approach enables the study of multiple evolutions of written forms, as well as the meaning the writer is intending to communicate.

This paper focuses on the emergence of hierarchical thematic progression in eight to eleven year-olds' writing, addressing the question: 'What does evolving use of theme position and modes of thematic progression in eight-eleven year olds' writing reveal about their 'gateways' into a 'different world of meaning'?'

\section{Materials and Methods}

To facilitate the analysis of thematic progression over time, a longitudinal design was adopted with a focus on texts written by the same children at regular intervals over two years. The labour intensity of linguistic analysis demanded a small sample size, in keeping with qualitative research design (Berry 1995; Kamberelis 2001). 


\section{Student sample}

A sample size of 24 was selected to be large enough to support the identification of significant trends but small enough to ensure the quality of linguistic analysis. Three genres were selected for scrutiny: argument, personal recount and explanation. Due to absences and attrition over time, the data sets for in-depth analysis totalled seventeen, fifteen and fifteen respectively.

The sample represented children across the ability range from four classes in two London schools. The schools, known to me (the researcher) as schools where I'd recently taught as a class teacher or supply teacher, were similar in terms of student intake, performance and religious affiliation, both followed the National Curriculum and were under local authority control. The age range (eight to eleven) was selected to be that within which a differentiated writing style is beginning to emerge but which is currently under-researched.

\section{Data collection}

Writing samples were collected during six 'sampling points' over two school years. To ensure consistency of teacher approach, I taught the class for lessons in which the sample texts were generated, facilitating 'thick description' (Geertz 1973, 6) of the context. Observations and discussions with teachers, in addition to my familiarity with the schools, enabled replication of typical writing conditions while ensuring that instruction was consistent across the classes. Finally, other texts produced in class were copied to ensure texts written at sampling points were representative of the children's usual writing. Texts written in the genres of argument, personal recount and explanation were chosen for detailed analysis to facilitate examination of theme use across different genres. 
Table 1: Overview of complete data set

\begin{tabular}{|c|c|c|c|}
\hline \multicolumn{4}{|c|}{ Data set one: Argument texts from research year 1 and 2} \\
\hline \multicolumn{2}{|c|}{ school A } & \multicolumn{2}{|l|}{ school B } \\
\hline $\begin{array}{l}\text { Emine, Jamal, } \\
\text { Omar, Darren, } \\
\text { Tanesha }\end{array}$ & $\begin{array}{l}\text { Millie, Abunima, } \\
\text { Osman, Sirdar, }\end{array}$ & $\begin{array}{l}\text { Kate, Abigail, } \\
\text { Mai-Shu, Tai }\end{array}$ & $\begin{array}{l}\text { David, Joe, } \\
\text { Juan-Carlos, } \\
\text { Shantelle }\end{array}$ \\
\hline \multicolumn{4}{|c|}{ Data set two: Personal recount texts from research year 1 and 2} \\
\hline \multicolumn{2}{|c|}{ school A } & \multicolumn{2}{|l|}{ school B } \\
\hline $\begin{array}{l}\text { Emine, Omar, } \\
\text { Darren. }\end{array}$ & $\begin{array}{l}\text { Millie, Abunima, } \\
\text { Sirdar, Natalie }\end{array}$ & $\begin{array}{l}\text { Kate, Abigail, } \\
\text { Mai-Shu, Tai, Leo, } \\
\text { Leon }\end{array}$ & $\begin{array}{l}\text { Juan-Carlos, } \\
\text { Shantelle }\end{array}$ \\
\hline \multicolumn{4}{|c|}{ Data set three: Explanation texts written from research year 2 and 3} \\
\hline \multicolumn{2}{|c|}{ school A } & \multicolumn{2}{|c|}{ school B } \\
\hline $\begin{array}{l}\text { Emine, Omar, } \\
\text { Tanesha }\end{array}$ & $\begin{array}{l}\text { Millie, Osman, } \\
\text { Sirdar, }\end{array}$ & $\begin{array}{l}\text { Kate, Abigail, } \\
\text { Mai-Shu, Tai, Leo, } \\
\text { Leon }\end{array}$ & $\begin{array}{l}\text { David, Joe,Juan- } \\
\text { Carlos }\end{array}$ \\
\hline
\end{tabular}

\section{Data analysis}

A single data set comprised texts written in the same genre by each individual at two sampling points (one year apart), with descriptive observations of each writing event. The first analysis focussed on a systematic description of theme position and modes of thematic progression in each text and was informed by the following principles:

(1) Trust the writer: in seeking to understand children's evolving means of linking textual units, all available cues were considered to understand the child's intended meaning.

(2) Consider the text's context: linguistic structures and features were considered within the context of the whole text and description of the writing event.

Ensuring the internal validity of the research required precise definitions of theme and modes of thematic progression. Halliday and Matthiessen $(2014,114)$ define 'Theme as a grounding for the clause as message' (op cit, 109) and identify it with reference to the experiential metafunction 'i.e. the first group or phrase ...that functions as a participant, 
a circumstance or the process' (op cit, 91). This constituent represents the 'topical' theme of a clause and, in the analysis, marked the end of what was viewed as thematic in a clause. As Halliday and Matthiessen (2014) stress, the topical theme may be preceded by elements, which have a textual meaning because of links to previous clauses (e.g. adverbials or conjunctions) or are interpersonal in nature making visible the writer's attitudinal or rhetorical stance (e.g. modal adjuncts such as 'definitely'). In deciding how much of a clause to count as thematic I, therefore, 'err[ed] on the side of generosity' (Berry 1995, 64; North 2005), and I also to restricted analysis to declarative main clauses. To facilitate analysis of the evolution of thematisation, separate categories were used to identify the types of topical themes and textual themes characteristic of each text (Berry 1995). In relation to the former, the distinction between predominate use of informational themes (foregrounding aspects of the topic) and interactional themes (referring to the writer or reader) (Martin 1986; Berry 1995) was particularly relevant. Danes' (1974) categories were adopted to identify the modes of thematic progression in each text.

The analytic frameworks generated were used to compare individuals' use of theme position and thematic progression from sampling point 1 to 2 and then to identify patterns of change in relation to that genre. Texts or sections of texts which were 'heterogenous' (or hybrid) (Fairclough 2000, 172; Kamberelis 2001) in relation to theme use/ thematic progression relative to children's previous writing or within the data set as a whole were identified. These hybrid sections were scrutinised to illuminate any external or internal factor potentially providing a gateway to new modes of construing knowledge and experience. Finally, genre-specific gateways were compared to identify generalised gateways. 


\section{Results}

Through the section to follow, generalised thematic change in each genre is presented in detail in relation to one pair of texts representative of the cohort as a whole, while gateways are discussed with reference to the texts or textual sections which proved key to their identification.

\section{Gateway 1: Appropriation of textual conventions and models of information thematisation}

\section{Context}

Literacy lessons leading up to both sampling point tasks had focused on the argument genre. Both schools modelled a textual structure characterised by an initial topic sentence followed by exemplification points. In school A but not school B the model was characterised by 'for' and 'against' sections with separate topic sentences for each.

Sirdar's (School B) Y4 argument

I think Y4 children should use pens to make there writing stand out.

They should use them because they don't break, whereas pencils break.

They should use them because they don't need to be sharpened but people spend time sharpening.

They should use them because they don't smudge whereas pencils do.

\section{Sirdar's Y5 Argument}

think Pokemon cards should be banned altogether. here are my reasons

firstly people mugg others just for their pokemon cards. Secondly people

break into eachothers houses just for pokemon cards. Another reason is that

they've banned them in school because of arguments once my classmates 
took half an hour just for one argument. The last reason that I am going to

give is people get paranoid about them one of my mates charlie hardly ever

plays with me because of that cardboard with silly pictures.

Topical theme

Textual theme $\quad=$ hypertheme

In all but two Y5 texts, changes in relation to theme reflected the adoption of a generic argument text structure, as exemplified in Sirdar's writing. The hypertheme, 'I think Pokemon cards should be banned altogether' facilitates adverbial reference (firstly, secondly...) to the central thesis which is no longer repeated from sentence to sentence. Consequently, the bulleted listing of points characteristic of the Y4 texts ceases and topical themes shift from being predominantly interactional (I, you, we) to informational (people, Pokemon cards, someone in my school) in nature. The resulting reduction of load on individual sentences is striking and seems to invite elaboration particularly because, like Sirdar, many children had interesting stories to share. Despite this, mostly (in 12 out of 17 cases) the prevailing mode of thematic progression remained one of 'thematic progression with continuous theme'. As in Sirdar's case, the central thesis 'I think Pokemon cards should be banned altogether' is recoverable in theme position throughout the text and is suggestive of the addition of new points rather than elaboration of existing ones.

The power of syntactic models was exemplified by the impact of a relatively abstract starter sentence incorporating a passive structure ('Recently Pokemon cards have been banned in our school') which I inadvertently suggested to a small group struggling to start their writing. When transferred to the children's texts, the ban itself became more prominent, inviting comment and elaboration through subsequent sentences: 


\begin{abstract}
Abunima's Y5 argument
Recently pokemon cards have been banned in our school but now this has happened nobody has nothing to do. Although they are banned many children still bring them in to school and when they are stolen we can't talk to the teachers otherwise we get told off for bringing them in...'
\end{abstract}

Syntactic model inadvertently provided by teacher Textual theme with an adverbial of concession expanding on previous sentence

The fact that such abstract nominalisations are challenging for children to produce independently is suggested by Abunima's shift into a more familiar mode of thematic progression for her remaining points: 'Another reason is that school is the only good place for children to trade cards... '.Informational themes characterised by nominalisation may not become part of children's writing repertoire for some years. However, syntactic models like the one suggested seem to offer a gateway to this abstract way of construing experience.

The three other children to establish hierarchical rather than additive modes of textual progression were those from school A, who organised their Y5 texts into 'for' and 'against' paragraphs. While such paragraphs were mostly characterised by single sentence points, in sections, these children seemed to sense the scope afforded by the textual unit of paragraph to expand a point across sentences e.g:

Janet's Y5 argument (extract)

Pokemon cards are also dangerous because if someone has got a Pokemon card that is really valuable, someone else that hasn't got that card will do something that isn't very nice to get the Pokemon card. People sometimes get 
stabbed by other people who want their Pokemon cards. On the news, I saw

someone who was beaten up badly because he had a really good pokemon card.

This gateway corroborates the social-semiotic argument that written conventions themselves play a role in shaping children's construal of knowledge and experience.

\section{Gateway 2: Depth of content knowledge}

In both research years, the personal recount texts were written a week after the arguments. In preparation, I shared a significant life story and provided an opportunity for the sharing of life stories with a partner before independent writing. Patterns in thematic changes from Y4-Y5 across the data set are exemplified in Tai's writing below. While neither school provided instruction in this genre, the orientation, complication and resolution narrative structure had been explicitly taught by class teachers earlier in Y5 and appears to impact on thematic options.

Tai's Y4 personal recount

The Big Accident

When I broke my arm I was five. I was walking upstairs to the toillet and when I came out I slipped on a banana peel. When I got to the bottom I was shouting. My Mum took me to hospital. I feel asleep and when I woke up I had a bandage on my arm

Tai's Y5 Personal Recount

A hole in one

one day when I came home from school I was really tired but I couldn't sleep. My mum was ironing and my dad was sitting down reading [the] 
newspaper. My little brother was just mukking about. After my mum had

finish ironing, she put the iron on the floor by the socket.

Then there was a power cut and the whole street was blacked out. Then, when everyone was panicing my little brother was calm. I knew there was something wrong and there was. There was a really strange smell and when the lights came on the iron had made a hole in the carpet, my little brother had plugged in the socket and the iron had made a hole. But now the hole is covered by my piano. And that is what I call a hole in one.

Textual theme

Topical theme

'Thematic progression with derived themes' characteristic of paragraph one.

Characteristic of thematic changes between Y4 and Y5 across the cohort (Appendix 1), a wider variety of time adverbials are employed, some of which ('after my mum finish ironing', 'when the lights came on') situate actions in relation to the recount's climax. Again characteristic of the whole cohort, in contrast to the predominant use of first person pronouns in $\mathrm{Y} 4$, in $\mathrm{Y} 5$ Tai uses his first paragraph to introduce the range of protagonists involved in the climax. Further, unusual across the data set and yet present in seven Y5 personal recounts, a non-human agent 'the hole' is made thematic in the final sentence. Tai's awareness of the complete narrative when writing individual sentences is evidenced by the self-correction in his original text (Appendix 2). After introducing the principal protagonists at the beginning of sentence 4 he originally writes 'Then', the starting point for the paragraph to follow. This is crossed out and replaced with the sentence beginning with 'after' which clarifies the position of the iron, vital to the climax. The 'thematic progression with derived themes' structure of the orientation 
means that the 'little brother' and 'iron' can be easily recovered through this section. Although the climax itself seems challenging to represent, sentences are strategically ordered to gradually reveal the brother's actions and the final resolution.

Three children demonstrate greater awareness of how to exploit rheme and subsequent theme to maximise the impact of their climactic event as illustrated in an extract from Abigail's Y5 recount about meeting her new-born brother:
Abigail's Y5 personal recount (extract)
We went to see my mum at the Whittington hospital. The doors were brightly
coloured with painted pictures on. My dad took me to a yellow curtain.
Behind it was my mum. I was happy to see her. Beside her, was a tank with
holes in it. It had a green little boy in it. I loved him.

\section{Theme}

\section{Rheme}

Simple Linear Progression between sentences $1 \& 2,3 \& 4,5 \& 6$ and $6 \& 7$.

While there was scant evidence of such syntactic flexibility in other children's texts, relative to the other data sets, there was more experimentation with thematic progression across the cohort in the Y5 personal recounts. This suggests that depth of content knowledge served as a gateway to new modes of thematic progression. Hierarchical modes of thematic progression require linguistic knowledge and dexterity but also clarity with regard to communicative intent. Children are likely to have frequently considered these life events and may have heard or re-told them repeatedly. Such reflection may facilitate analysis of the event during writing, its separation into constituent units and re-ordering according to writer agency. 


\section{Gateway 3: Writer reflection on and analysis of content knowledge}

Discussion prior to the Y5 and Y6 Explanation task drew on children's school-based instruction, but also aimed to develop content knowledge. For the Y6 task, building on school-based learning about the Victorian period, I provided a briefing sheet about school life in late Victorian Britain, along with organisational suggestions (Appendix 3). Emine's explanation texts are characteristic of change in relation to use of theme position and modes of thematic progression from Y5 to Y6.

Figure 1: Emine's Y5 explanation

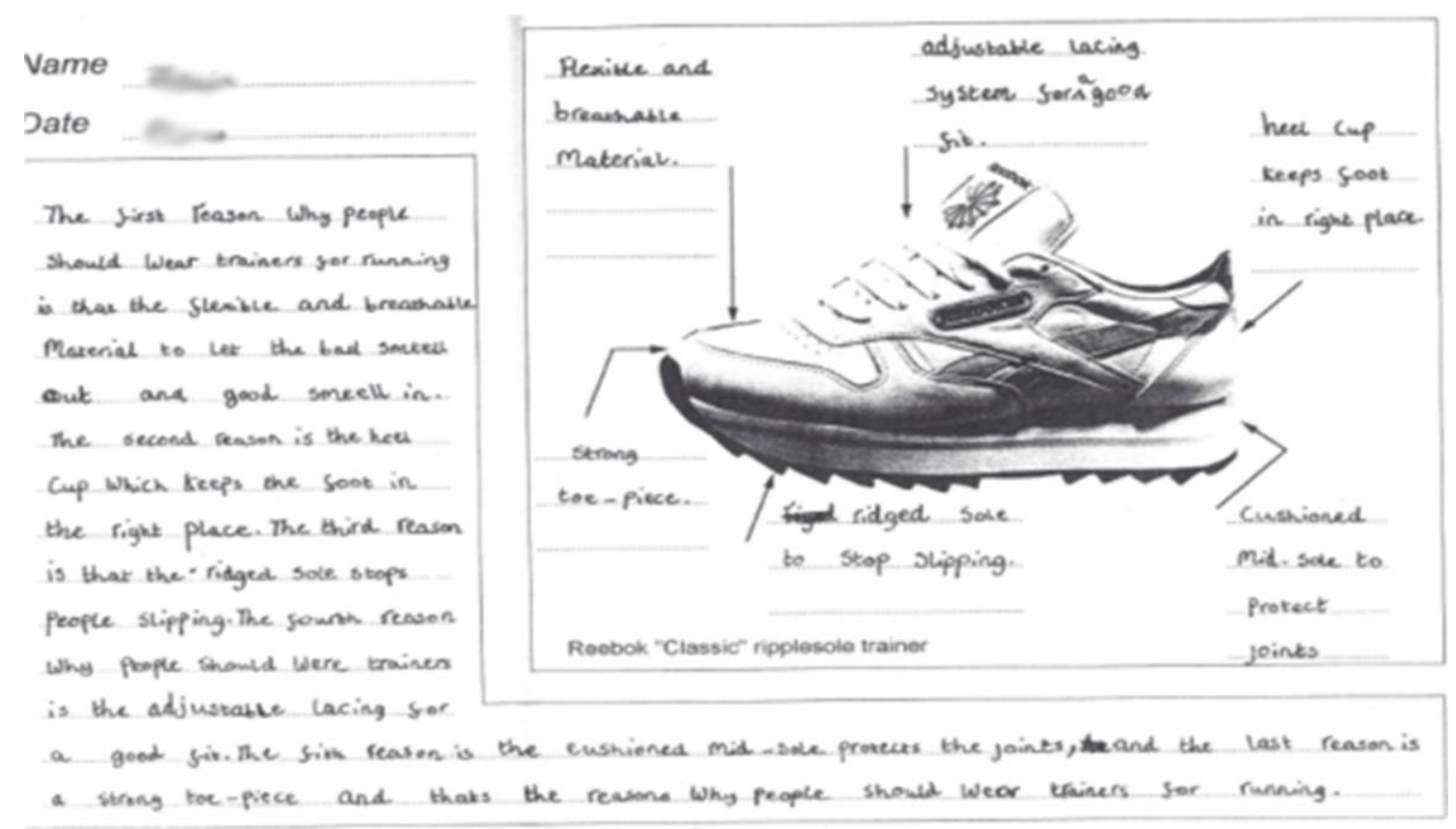


Figure 2: Emine's Y6 explanation

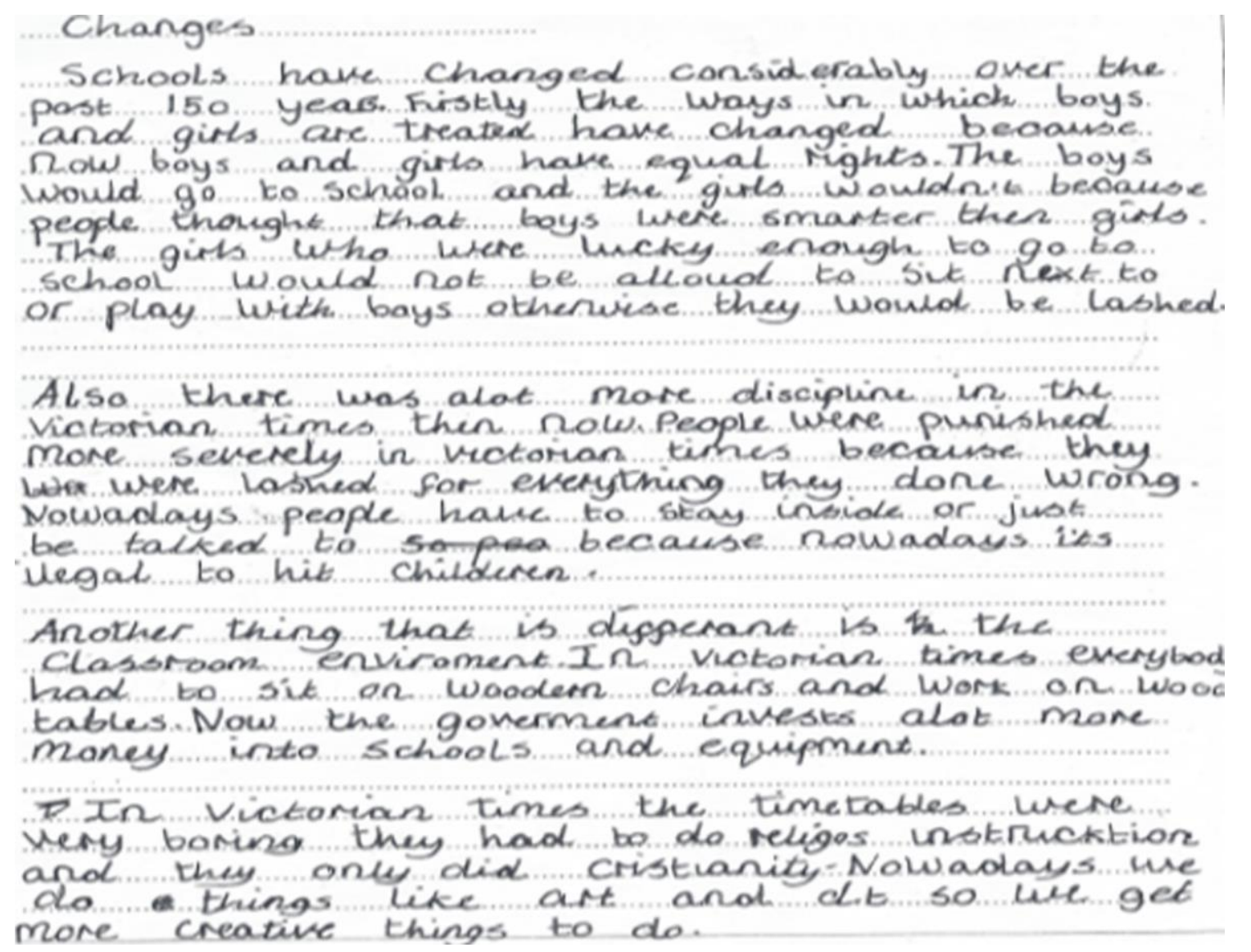

Representative of the cohort, Emine's Y6 text is characterised by a wider range of text structuring resources and a broader vocabulary than was in evidence in her Y5 explanation or argument. Similar to all but five of the participating children, and in contrast to her writing in Y5, Emine structures her Y6 explanation in paragraphs, sentence themes through the first paragraph (the boys, girls who were lucky enough to go to school) expanding on the paragraph's hypertheme 'the ways in which boys and girls are treated'. Similarly, other children endeavoured to establish lines of discussion across paragraphs, particularly by using 'text-internal' adverbials, such as 'I mentioned earlier', 'this', 'these changes' (see Appendix 4). These contrast with the generic adverbials (firstly, my next reason) which characterised the Y5 texts. Further, in common with the cohort, Emine's Y6 text demonstrates greater confidence with informational thematisation and the exploitation of topical theme position. While the 
passive, nominalised hypertheme of the first paragraph 'the ways in which boys and girls are treated has changed' is partially modelled on the briefing sheet, the lengthy noun phrase with embedded relative clause 'the girls lucky enough to go to school...' is her own, as are other abstract informational themes such as 'the government' (paragraph 3, line 4). Finally, and again in common with ten out of fifteen of the cohort, her Y6 text is characterised by all three modes of thematic progression while her Y5 text by just one. Additionally, by Y6, children are using all three modes both more conventionally and flexibly. For example, 'simple linear progression' in the Y5 arguments was often characterised by 'run-on' sentences, the second clause complex juxtaposed to the first without punctuation. By Y6, this is on the decrease and anaphoric reference to previous sentences on the increase.

Particularly evident in this data set are texts like Emine's, which are hybrid in nature, some sections representative of new modes of thematic progression with others more characteristic of earlier writing. The 'relatively hybrid/creative' (Fairclough 2000, 172) sections in these texts illuminated the identification of a further gateway. As explained above, the sentence-starter 'the way in which girls and boys were treated' was modelled on the briefing sheet as a potential topic for discussion. Like the syntactic model discussed earlier, it is a statement which demands elaboration across subsequent sentences, while the reference to 'boys' and 'girls' is suggestive of themes in sentences to come. In Emine's Y6 explanation, this results in a paragraph characterised by more deliberate exploitation of topical theme position than is evidenced through the rest of the text. Paragraphs beginning with the same phrase were evidenced in nine children's similarly hybrid texts.

The impact of the model is interesting linguistically, suggesting that production of abstract informational themes incorporating passive structures remains challenging 
up until the end of the research period; children readily draw on models, but few produce their own. It may seem therefore that linguistic models provide a gateway to thematic progression, but analysis of this data set suggests this is only partly true. The briefing sheet provides four potential topics for discussion, 'The way in which boys and girls are treated' being the last. A full paragraph model was provided for the 'classroom set up' topic but was drawn on by just two children. That 'the way in which boys and girls are treated' re-appears nine times suggests its subject matter was of particular interest and one which children were motivated to pursue, as evidenced by the way the topic is expanded over multiple sentences through the use of challenging linguistic forms as seen in the final sentence in Emine's first paragraph and Millie's paragraph below:

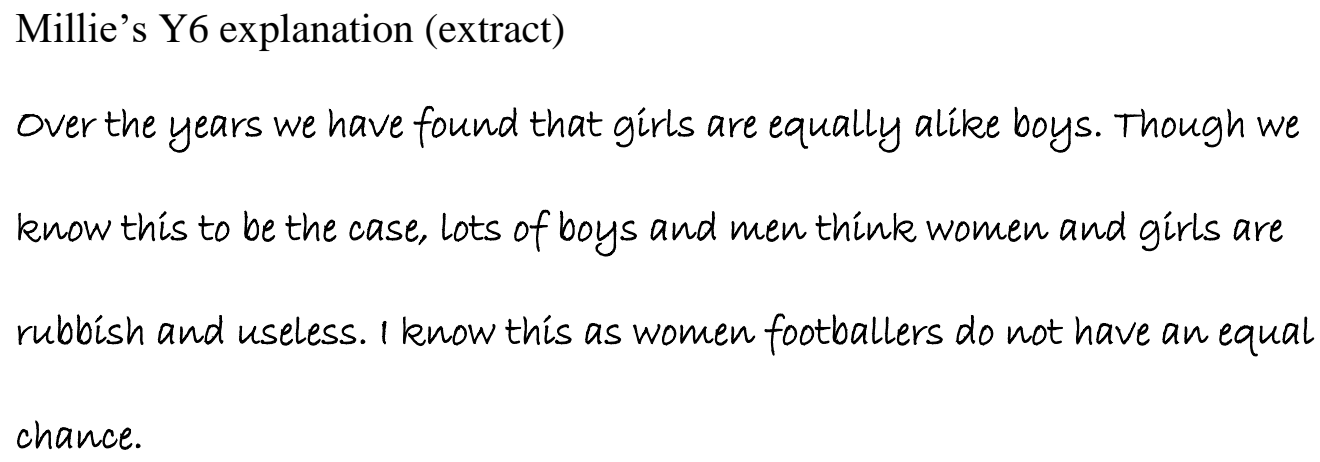

The connection between personal interest and experimentation with theme position is also evidenced through the re-introduction of personal pronouns in many of the Y6 explanations. In the Y4 arguments, 'I think' was used by many as a default sentence starter but was less in evidence in the Y5 arguments and explanations. However, personal pronoun use is deliberate in many of the Y6 explanations to express opinion (as above) or to hypothesise, 'I think they thought playing with girls would lead to hanky-panky' (Sirdar), or to directly address the audience. For example, working in separate classes, Leon and Joe both craft similarly playful ways to introduce a new topic while simultaneously addressing an imagined less knowledgeable peer reader. 
Leon's Y6 explanation (extract)

If you thought staying in at playtime was hard try taking being hit by a cane 8 times.

Joe's Y6 explanation (extract)

on the subject of lashes - the punishment was pretty hard - you would get whipped just for blotting ink. Here is a list of punishment... pretty bad isn't it?

The gateway here is the writer's reflection on and analysis of content leading to clear communicative intent. The result is not the acquisition of established writing conventions but rather an appropriation (in all cases more appropriate to the context than the modelled sentence starters) reflective of the writer's textual history and emerging 'writer voice'.

\section{Discussion}

The research provides unique insights into the interdependence of linguistic knowledge, content knowledge and writer agency in eight to eleven year olds' re-making of hierarchical modes of thematic progression. Data analysis has identified three complementary 'gateways' or 'special ways in' to a 'different world of meaning' (Halliday 1990, 98). The first concerns the Appropriation of textual conventions and models of informational thematisation. Findings corroborate that knowledge transformation should indeed be understood as 'in part at least, about linguistic development specifically in terms of how sentences are shaped and patterned' (Myhill 2009, 41). Generic textual structures, paragraphs and shorter sentences became increasingly embedded over the course of the research period and changes were suggestive of more hierarchical modes of thematic progression as evidenced in the Y5 
personal recounts and in Janet's Y5 argument. Models of informational thematisation (Y5 argument; Y6 explanation) were a more direct gateway, providing an alternative, more abstract perspective on content knowledge and how it might be elaborated across sentences to follow. The second gateway Depth of content knowledge confirms that 'knowledge transformation' is more likely when writing about topics of personal expertise (McCutchen 2000) about which children have greatest depth of understanding and authority relative to the reader. Unlike the older children discussed in SFL research whose forays into hierarchical modes of thematic progression reflect evolving historical or scientific reasoning, these younger children are more likely to project across sentential boundaries to indicate causality between events or to flag their chosen focus when writing about the personally familiar and important. The third gateway Writer reflection on content knowledge or writing task glosses the act of reflection and writer agency. All hybrid sections manifest the writer's active engagement with and analysis of content knowledge. This personal meaning-making lies at the heart of the learning process and it is the process of representing one's own reflection and analysis which unlocks the affordances of HTP for the writer.

All three gateways played a more or less direct role in all hybrid texts produced, due to interdependence between the linguistic, cognitive and writer agency in the learning process. Where models of informational thematisation triggered experimentation with theme position, children's conceptual understanding of content matter changed as a result; conversely, new perspectives on content material (triggered by the writing process) resulted in changed use of theme position. That is, changes in form are always accompanied by commensurate shifts in understanding of content material and vice versa (e.g. Kress 1996; Van Drie and van de Ven 2017). Further, the data illuminated what Halliday $(1990,61)$ terms 'a dialectic' or leap-frogging between 
form and meaning; in the personal recount texts, children's appropriation of the narrative text structure was suggestive of a conceptual framework for the event which in turn resulted in hierarchical modes of thematic progression. Whatever the trigger, the re-making of form is driven by the writer's personal reflection on content and/or audience. Each remaking represents a momentary transformation of the child's linguistic resources, their understanding of content and their ability to manipulate both. Through these moments, a unique writer voice emerges.

\section{Conclusions, implications for practice and further research}

The evolution of thematic progression over the research period is linked to syntactic and textual conventions becoming increasingly embedded in children's writing repertoire. Such structures invite hierarchical modes of thematic progression. The findings illustrate how adult models of informational thematisation can scaffold children's production of modes of hierarchical thematisation. However, the realisation of the affordances of the form demands individual analysis of content knowledge; it is this act of meaning-making which gives rise to the writer's idiosyncratic conceptual framework, the representation of which leads to their own 're-making' of hierarchical thematisation. Transformation of content knowledge and writers' linguistic resources are mutually constitutive in this act and reveal writer reflection, agency and voice suggesting that hierarchical modes of thematic progression are learnt, as they evolved, as a representation of reflection on knowledge or experience so as to better understand it.

In terms of informing practice, the research points to the importance of raising awareness of the role that manipulation of theme position can play in the process of learning to use writing purposefully as a tool for thinking.

The research reveals that non-temporal modes of adverbial fronting, abstract nominalisations and passive structures are challenging to produce independently but 
also that children are alert to the semantic affordances of contextualised models of such structures which they readily re-accentuate for their own meaning purposes. Writing frames have been rightly critiqued for giving rise to formulaic writing, stripped of writer voice (e.g. Barrs 2019) providing, as they do, a pre-determined theme and, therefore, little scope for the writer to more than recall knowledge. However, the research suggests ways that less prescriptive pedagogic practices could be re-crafted to foster experimentation with theme position in the focus age group.

With regard to personal writing, data set two suggests the positive impact of narrative text structure on the Y5 personal recounts providing the structural framework to write with the event's climax firmly in mind. Mentor texts (authentic, effective texts in the focus genre) of personal journal writing or blogs could be carefully selected to model this generic structure and to draw attention to effective use of elements of setting or sensory details (sights, smells, feelings) in theme position as alternatives to adverbials of time. Children's appropriation of such themes could raise the cognitive challenge of personal writing as well as promote the cathartic benefits of re-visiting the familiar from new perspectives.

With regard to non-fiction writing, research in the SFL tradition in Secondary classrooms highlights how carefully constructed teacher-student interactions in e.g. the science or history classroom inducts students simultaneously into the subjects' concepts and the linked thematic structures used to represent them, which are frequently characterised by abstract nominalisations (e.g. 'The separation of church and state...', van Drie and ven de Ven, 2017, 537). After similar opportunities for oral rehearsal in the primary classroom, key, lesson-specific noun phrases could usefully be generated as 'sentence starters' opening up a range of ways to represent semantic relationships between elements of content knowledge across a series of sentences. 
In terms of research methodology, the research highlights the potential rewards to be gained from applying Halliday's 'magic gateways' metaphor to the study of language learning. In the process of identifying gateways, the researcher's focus is on the intertwined contextual variables which appear to impact on the text producer's linguistic choices. The hybrid texts which result from the fusing of new and more familiar discourses provide insights into the writer's idiosyncratic ways into new modes of meaning which could easily be overlooked by larger scale, randomised controlled trials of pedagogic interventions. As 'material instantiations' (Jewitt 2008, 259) of the writer interest and agency, not only are such hybrid texts potentially revelatory to the researcher of novice writing, but also to practitioners seeking to design challenging and personally relevant writing tasks for particular groups of children.

\section{References}

Barrs, Myra. 2019. "Teaching bad writing”. English in Education 51 (1): 18-31.

Barton, David, Mary Hamilton, and Rosalind Ivanic. 2000. Situated Literacies: Reading and Writing in Context. London: Routledge.

Bearne, Eve. 2017. “Assessing children's written texts: a framework for equity". Literacy 51 (2): 74-83.

Bereiter, Carl, and Marlene Scardamalia. 1987. The Psychology of Written Composition. Hillsdale, NJ: Lawrence Erlbaum Associates.

Berry, Margaret. 1995. "Thematic options and success in writing”. Thematic Development in English Texts, edited by Mohsen Ghadessy, 55-84. London: Pinter Publications.

Christie, F. 2010. "The ontogenesis of writing." The Routledge International Handbook of English, Language and Literacy Teaching, edited by Dominic Wyse, Richard Andrews and James Hoffman, 146-158. London: Routledge. 
Coffin, Caroline. 2006. "Learning the language of school history: the role of linguistics in mapping the writing demands of the secondary school curriculum." Journal of Curriculum Studies 38 (4): 413-429.

Danes, Frantisek. 1974. "Functional sentence perspective and the organization of text." Papers on Functional Sentence Perspective, edited by Frantisek Danes, 106-28. The Hague: Mouton.

Dyson, Anne Haas. 2004. "Where are the childhoods in childhood literacy?" The Routledge Falmer Reader in Language and Literacy, edited by Teresa Grainger, 84106. New York: Routledge Falmer.

Ellis, Susan. 2005. Review of 'The Best of Language Matters.” Literacy 39 (1): 54-55. Edwards, Gillian, and Jane Jones. 2018. "Boys as writers: perspectives on the learning and teaching of writing in three primary schools." Literacy 52 (1): 3-10.

Fairclough, Norman. 2000. "Multiliteracies and language: orders of discourse and intertextuality." Multiliteracies: Literacy Learning and the Design of Social Futures edited by Bill Cope and Mary Kalantzis. London: Routledge.

Fisher, Ros. 2006. "Whose writing is it anyway? Issues of control in the teaching of writing." Cambridge Journal of Education 36 (2): 196-206.

Gardner, Paul. 2018. "Writing and writer identity: the poor relation and the search for voice in personal literacy." Literacy 52 (1): 11-19.

Geertz, Clifford. 1973. The Interpretation of Cultures: Selected Essays. New York: Basic Books.

Halliday, Michael. 1993. "Towards a language-based theory of learning." Linguistics and Education 5 (2): 93-116.

Halliday, Michael, and Christian Matthiessen. 2014. Halliday's Introduction to Functional Grammar. $4^{\text {th }} d$. Taylor and Francis. Kindle Edition. 
Harris, John and Jeff Wilkinson. 1986. Reading Children's Writing: A Linguistic View. London: Allen and Unwin.

Hawes, Thomas. 2015. "Thematic progression in the writing of students and professionals." Ampersand 2: 93-100.

Jewitt, Carey. 2008. "Multimodality and Literacy in School Classrooms." Review of Research in Education 32: 241-267.

Kamberelis, George. 2001. "Producing of Heteroglossic Classroom (Micro)cultures Through Hybrid Discourse Practice.” Linguistics and Education 12 (1): 85-125. Kelly, Alison and Kimberly Safford. 2009. "Does teaching complex sentences have to be complicated? Lessons from children's on-line writing." Literacy 43 (3): 118-122. King, Carole. 2004. "Can teachers empower pupils as writers?” The Routledge Falmer Reader in Language and Literacy edited by Teresa Grainger, 289-304. New York: Routledge Falmer.

Kress, Gunther. 1994. Learning to Write. $2^{\text {nd }}$ ed. London: Routledge.

Kress, Gunther. 1996. "Writing and Learning to Write.” The Handbook of Education and Human Development, edited by David Olson and Nancy Torrance, 225-256.

Oxford: Blackwell.

Lambirth, Andrew. 2016. "Exploring children's discourses of writing." English in Education 50 (3): 215-232.

Lemke, Jay. 1990. “Talking Science: Language, Learning and Values.” Westport: Ablex.

Lim, Eunsook and David Kellogg. 2008. "The Ascent of the Concrete: Grammatical Reification in Science Teaching Exchanges and Episodes." Language and Education 22 (3): 206-221.

Moll, Luis, Sandra Soto-Santiago, and Lisa Schwartz. 2013. "Funds of knowledge in changing communities." Wiley International Handbook of Research in Children's Literacy, Learning and Culture, edited by Kathy Hall, Teresa Cremin, Barbara Comber and Luis Moll, 172-183. Wiley Blackwell. 
McCutchen, Deborah. 2010. "Knowledge, Processing and Working Memory:

Implications for a Theory of Writing." Educational Psychologist 35 (1): 13-23.

Myhill, Debra. 2009b. "Becoming a designer: trajectories of linguistic development."

The Sage Handbook of Writing Development, edited by Roger Beard, Debra Myhill, Jeni Riley and Michael Nystrand, 402-414. London: Sage.

Perera, Katherine. 1984. Children's Writing and Reading. Oxford: Blackwell.

Schwartz, Lisa. 2014. "Challenging the tyranny of the five-paragraph essay: teachers and students as semiotic boundary workers in classroom and digital space." Literacy 48 (3): 124-135.

van Drie, Jannet and Piet-Hein van de Ven. 2017. "Moving ideas: an exploration of students' use of dialogue for writing in history." Language in Education 31 (6): 526542. 
Appendix 1: Analytic framework for the personal recount texts

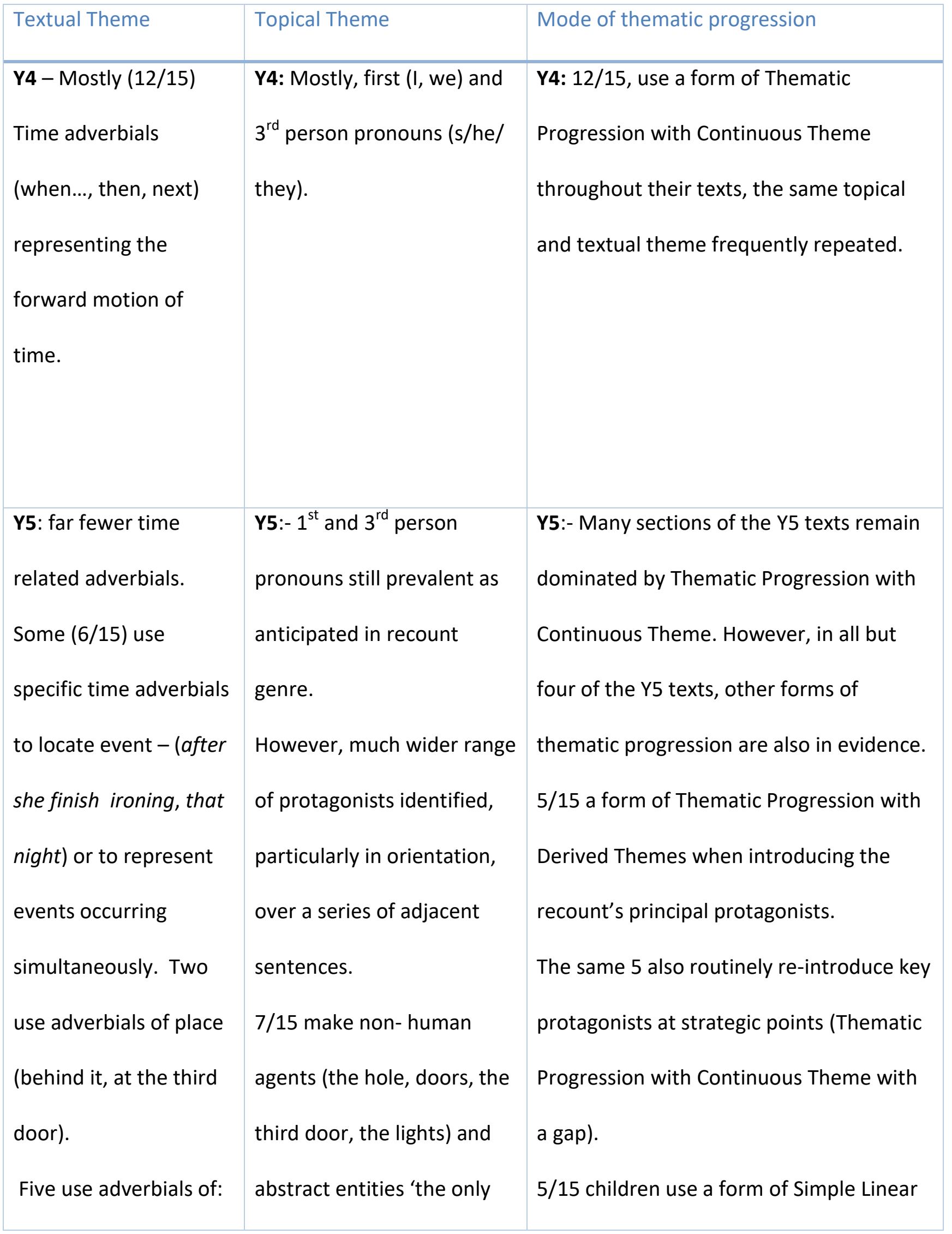




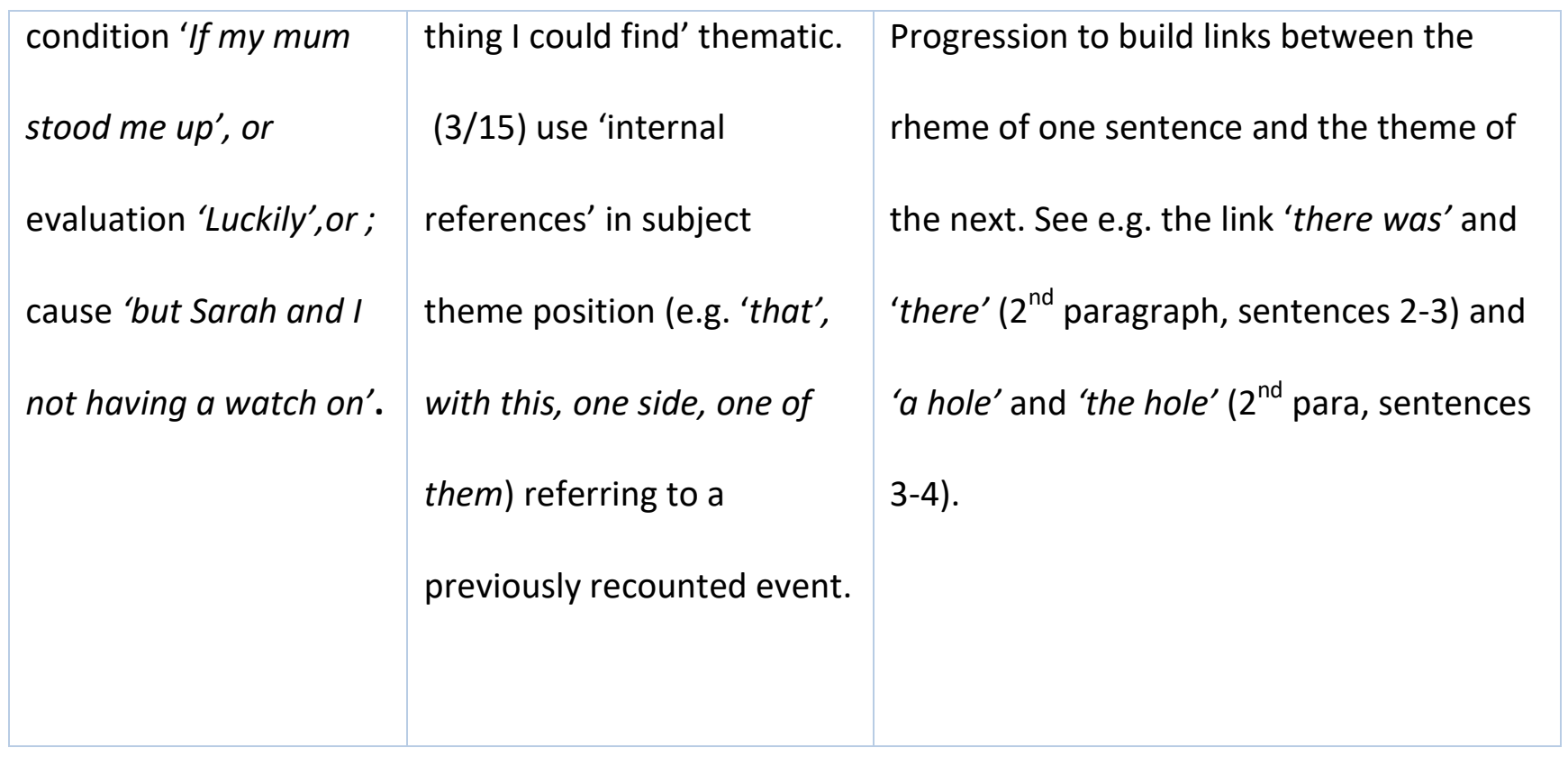


Appendix 2 Tai's hand-written personal recount

A wide ir one.

One day when I came home fro un s really tired but ! could n: sleep. My mum uss severing and in dod was sitting dow reading na My life brother was just mus about After my mun had on the poor by the socket.

Then the we was a power at the and the whole stet was blacked out

Then when everyone was ry y little bother vols calm I the Here was something wrong and there wo There was a really strange smell and when the lights cane on the wort y had made a hole in the cluoceder, my the title brother had plugged mode a hade. But now the hole is covered by my point. And 
Appendix 3 - Y6 briefing sheet

Task: An explanation of the differences between school life in the Victorian times and school life today.

The worksheet shows a photograph, a picture, a timetable and a set of rules from Victorian schools. Look carefully all the information and explain:

a. what has changed;

b. how it has changed;

c. why you think it has changed.

You might want to think about the following themes:

- The classroom environment (how the tables are set-out, classroom displays etc) and things (resources) in the classroom.

- The subjects which are taught and how they are taught.

- Discipline-does it seem as though the teachers are more or less strict than they are today.

- The ways in which boys and girls are treated.

Try to use information from all parts of the sheet.

You might want to start your writing like this:

Victorian schools differed in many ways from schools in the 21st century.

Or

Schools have changed considerably over the past 150 years.

Then, introduce the themes you will be discussing in the main ps:t of your explanation.

Remember if you can, discuss what has changed, how it has changed, and why it has changed.

Firstly Victorian classrooms were set up very differently. (What) The tables were..........In today's classrooms they tables are........(How) These changes have occurred because...... (Why) 
Appendix 4: Analytic frame for Explanation texts

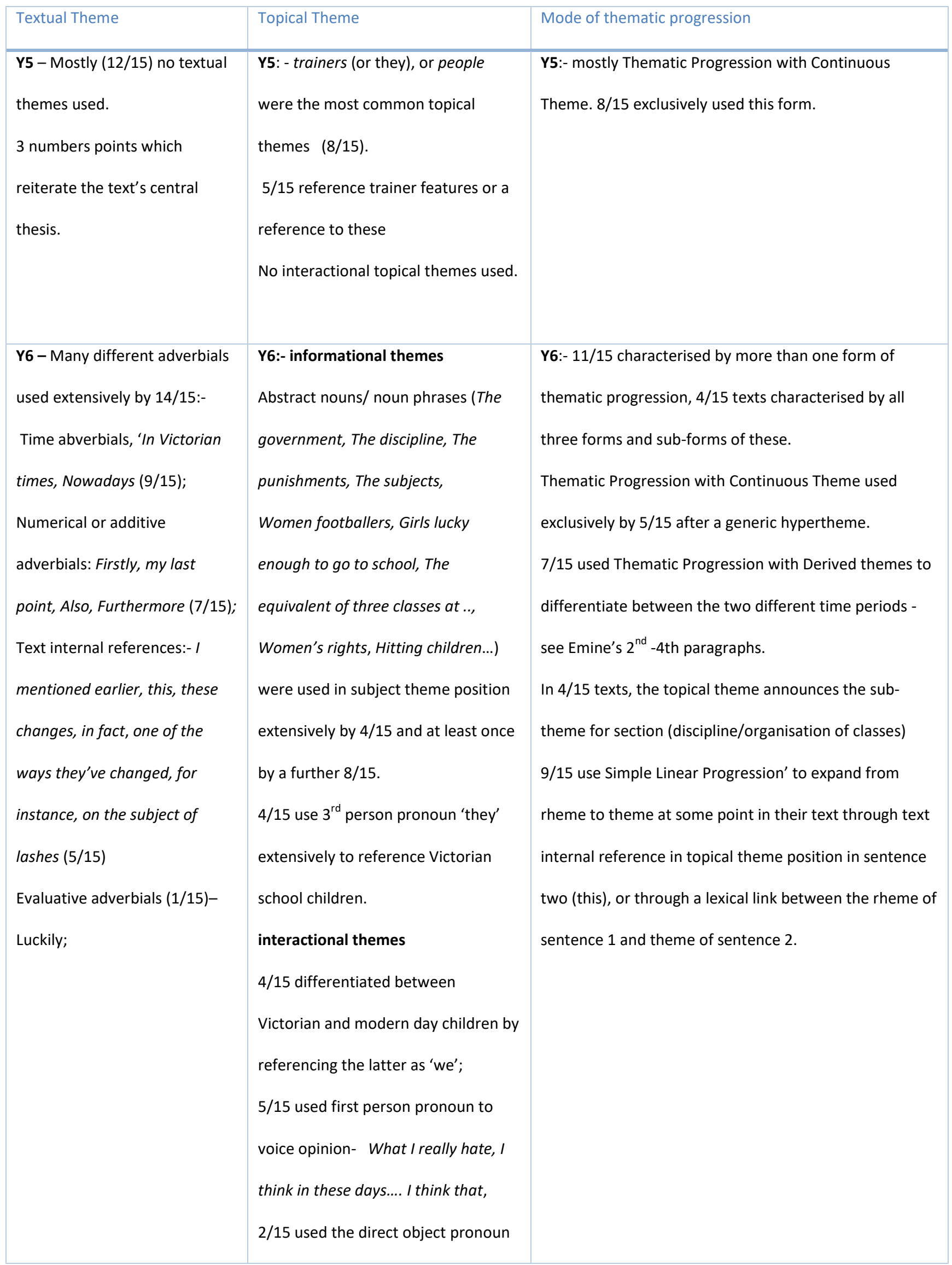




\begin{tabular}{|l|l|}
\hline 'our' alongside e.g. 'classroom/ \\
schools/ timetables \\
$3 / 15$ used the pronoun 'you' to \\
address a peer audience:- If you \\
thought staying in at play times is \\
hard, try...
\end{tabular} \mid

